\title{
Theoretical modeling of the logical-procedural system organizations of the history of society
}

\author{
Maxim Bakhtin ${ }^{1 *}$, Nikolay Rybakov², Natalya Yarmolich $^{2}$, and Irina Sokolovskaya ${ }^{3}$ \\ ${ }^{1}$ International Professorial Club (Italia), 97100, via Velardo, 35, Ragusa, Italia \\ ${ }^{2}$ Pskov State University, 2, Lenin square, Pskov, 180000, Russia \\ ${ }^{3}$ State University of Management, 109542, 99 Ryazan Ave., Moscow, Russia
}

\begin{abstract}
This article focuses on the metaphysical foundations of educational philosophy. They are considered as the sources of future human modeling and the commission of certain actions. The article explores the evolution of these principles in the development of human civilization. The causality principle is considered as the entity's fundamental ontological characteristic. It suggests that a human being can realize his desire for freedom only by submitting his life to the universal objective law. In the causal perspective, any phenomenon is considered as the consequence of a cause and at the same time as the cause of some other consequence. The model of the world of primitive man could not and did not contain a picture of nature as a certain arrangement of phenomena, united by unified causeand-effect laws. However, it does not mean that our primitive ancestors did not imagine the world around them without the categories of order, just in his mind, there was a different order.
\end{abstract}

\section{Introduction}

Epistemological standards, ideals, and norms of modern knowledge are reference points for socio-historical knowledge; generate the corresponding reflection of logical-processual history characteristics. Today, this concern to a maximum extent the history dynamics and development: the classical scheme revision of epistemological relation ("subject/object") implies the appeal to the integrity of the determinants of knowledge. The specificity of the vision of historical procedurality changes in such a way that "lifestyle", the anthropological " background knowledge " of modernity with its dialogics, the theme of action and responsibility, the ethics of discourse, the ethics of the human species are directly included in cognition and discursive practices [1].

The purpose of this article is to consider the question of the relation between free will and the normative order, as well as the possibility of constructing social reality and a single unified world. The article concentrates on the transition from the causal order to the normative one of the historical process throughout the 20th century. It states the hypothesis that in the 20th century the world has entered the era of controlled history, and consequently the causal order is rapidly being replaced by the normative order, in which the historical

* Corresponding author: universdoktor@gmail.com 
process is increasingly planned and predictable, where historical events and phenomena are more likely the embodiment of a preconceived plan of action [2].

In this regard, the socio-philosophical position to the epistemology of historical processes should be organized in a complex correlation of vital organic and conceptual-discursive characteristics, taking into account not only dialogical but also destructive programs and strategies to tradition [3].

\section{Problem statement}

Indeed, the cognitive significance of the principle of historicism, without which it is impossible to construct epistemology of the processes of history, first of all, consists of the requirement to consider nature and a social life that are continuous in time. And just as space and time implementation continuity has a complex and diverse character, the application of the principle of historicism requires both general and special patterns of the flow of time in nature and society. Due to the ontological inhomogeneity of time, which is found in the variety of material systems temporal properties, in each specific case, it is necessary to clarify the specifics patterns of transition from the old to the new.

However, within the epistemological field of the procedural organization of history itself, it makes sense to distinguish between the historical tendency of epistemology and the modern conception, which is all the more significant when the address to the difficult marking definition of modernity and epistemology subject and status "prejudices". In this case, first of all, we should take into account the fundamental importance of the "epistemological- turn" that is associated with the name of M. Foucault [4].

The question is in the most general terms of the extreme importance of interpretation as a basic epistemological procedure of humanitarian-historical cognition. The relationship between foundationalism and relativism acts as a distinguisher in contemporary epistemological debates. Consequently, a fundamental question arises about the possibility of both positions dialogue: if such a dialogue is not possible, then the problem of the historical integrity and a holistic view of historical processes will become even more acute. In such a complex situation, systemic analysis and consistently built typology of interpretations in socio-humanitarian cognition provide an opportunity to identify the theoretical epistemological dominant in humanitarian cognition, to substantiate the understanding of interpretative prerequisites and the heuristically -creative nature of interpretation [5].

\section{Materials and methods}

The methodological basis of the work is the principle of historicism, dialectical unity, and continuity of historical epochs. The method of comparative analysis of two ontological principles, normativity and casualty is used. The following scientific methods are also used: dialectical, historical and substratum, structural and functional, systemic and variantmodeling. Methods and principles of phenomenology, historical hermeneutics, philosophical dialogue, and principles of cultural-historical comparative studies are applied.

The continued increase in the concentration of capital on the planet led to a situation in the middle of the XX century when guided history became not only possible but necessary. Finally, for the first time, humanity approached the possibility of creating a United World without Political Borders or National Government. At the beginning of the 21 st century, new technological possibilities have emerged, and the 6th technological way has begun to take shape when most of the physical labor will be performed by robots. This opportunity has led to the need to construct a new social structure. The need for the middle class has now disappeared. There is still a need for highly skilled work of a limited number of people. From 
that point on, the normative order began to dominate the casual order more and more. On the agenda was the creation of a single integrated world with a single world government, currency, legislation, etc. Humanity has come very close to the question of what kind of force will emerge as the architect and designer of this United World [6].

The development of the cause-and-effect series occurs as a smooth transition from one possible world to another. The act of freedom is a break in gradualism that irreversibly transports us into another world, immediately created by this very act. And here we are not talking about the cause, but rather the guilt. We are responsible for this transition, we have created this world and we are responsible for the fact that it now exists. At the same time, the guilt is not understood in the moral-evaluative sense, but in the ambivalent (metaphysical) sense, for the birth of good or evil out of our deeds is equally likely. Therefore, responsibility does not mean punishment, but the consciousness of one's active participation in the life, one's involvement in existence.

The systemic analysis of the specifics of the interpretation functioning in understanding the history processes allows keeping current the fundamentally important problems of epistemology. To expand the problem field of the history epistemology, we can say that consistent use of the principle of interpretation of the philosophical text of history and historical processes can be creatively used to understand the ideas of philosophical dialogue at the level of cultures and national traditions, that is important to establish the understanding of cultures and today's world communities. The categorial and methodological analysis of ideal and real objects of socio-philosophical understanding of history gives the possibility to set the problem of responsibility ("science ethics"). Respectively, the deed theme introduces the responsible and constructive representation of the tendencies of development of modern subjectivity [7].

Thus, it makes sense to analyze the logical-process epistemology of history in such a way as to simultaneously distance ourselves from the extremes of "foundationalism" and "relativism". On the discursive terms, there is a move toward value-oriented strategies of understanding; it implies growing attention to intertextual programs of interpretation. The scientific project we substantiate together represents an essential invariant of the historical processes epistemology based on hermeneutics -dialogical constructions. This makes it possible to upbuild a unifying perspective that modern social philosophy lacks - to understand epistemology as a directly realized experience of the formation and genesis of historical knowledge. As a result, we can speak not only of epistemological programs dialogue within the meaning of the historical processes logic but also of the well-known productivity of the "conflict of interpretative schemes": the current strategy of modern semantic genesis while preserving the universal structures of cognition and its value intentions is constructed. Epistemology turns out to be the connecting element that holds the space of cognition in unity - thereby social philosophy and the history philosophical epistemology regain the generic beginning, modern philosophy is impossible without it [8].

A "trans-epistemological discourse" of the processes of history is formed: in addition to the formational and linear understanding of history, the facts that "fall through" the classical text of the history philosophy are analyzed: (organic matter, body, landscape, other some). Understanding the history processes, within the discursive analysis of social philosophy, is oriented in a reflexive-topological way. It is thus worth considering that the newest epistemology is "ontological" ("eventful") oriented. It is no coincidence that there has been increasing attention not only to the legacy of the "organic school" of history but also to postclassical ontology in the field of philosophy. (A. Badiou, A. Bibikhin, V. Podoroga), which inherits a sustained interest in being-data throughout the XX century (A.F. Losev, G.G. Shpet, M. Heidegger, A.N. Whitehead, G. Bachelard) [9]. 


\section{Results and discussion}

To understand the modern historical processes epistemology it is important to keep in mind the transitional positions and "transformed forms" of socio-philosophical knowledge - those positions that occupied a borderline or peripheral place in classical epistemology. After all, in its extreme manifestations the ultimate "subjectivism" can be conceptualized as "objectivism" or "positivism. What is required, therefore, is an epistemology of the phenomenon of modernity itself. The definitions of virtual reality as an epistemological project of the "project of the future" are important. In any case, it is necessary to take into account classical and post-classical strategies of formation of historical epistemology in the sense that it includes genetically different universals and constants of historical knowledge today.

Thus, it can be argued that the specificity of social subjectivity vision, as well as individual regions of history, micro-historical formations, significantly change when the anthropological "background knowledge" of the modernity is directly included in the cognition with its dialogical character, the action theme, and responsibility, discourse ethics, "applied" themes of understanding the problems of genetic engineering, anti-psychiatry, euthanasia - everything that can be called the new presence of history. It is these "throw-ins" of vital-existential material into the space of philosophical reflection of history that "make" modern philosophy of historical process.

This is more important because the topological reflection is the actual form of thinking in the space in which there is an interlacing of attitudes and meanings. (V.V. Savchuk. Topological reflection. M., 2012). Thus, a critical "epistemology of epistemology" is needed, taking into account not only dialogical and constructive but also destructive programs and strategies to historical tradition - this may be relevant to the understanding of history and historical knowledge in general.

It should be recognized that the general epistemological space of modernity is in a situation of contradiction and destruction of classical boundaries and rubrics. Therefore, it makes sense to distinguish between the tendency of historical epistemology and modern concepts of historical epistemology. This is especially significant when it makes sense to distinguish between the historical tendency of epistemology and the modern conception, that is all the more significant when the address to the difficult marking definition of modernity and epistemology subject and status "prejudices" - the term itself requires consistent categorical analysis and conceptualization (in this case we should take into account the fundamental importance of the "epistemological - turn" associated with the name of $\mathrm{M}$. Foucault). In other words, a new methodology should be applied to a new sociality and a new historical material. Otherwise, it will be impossible to define at least general perspectives of contemporary social dynamics and, even to formulate the best option for the realization of meaningful perspectives of historical existence. Last but not least, this applies to the existence of contemporary communities, which have an increasing impact on the "big society" [10].

It should first be a recognized fact that such definitions as "organics of the background knowledge" and with it, most essentialist definitions of social matter, end up on the list of primordialism, whose positions on many points are fundamentally displaced by social constructivism. This has its explanation, which consists not only in the idea of the "operational" of history but also in the social sense of the danger of organic images of social existence, which is associated with the creation or simulation of the supremacy of social body threat. In this view, Europe, for example, may seem like an island attached to the grandiose body of an entirely different empire: the Mongol empire. In that view of the world, Europe, for example, may seem to be an island attached to the grandiose body of an entirely different empire: the Mongol Empire. 
It is worth pointing out a remark on a similar occasion: Europeans who first saw Mongolia imagined that the center of the world is not Rome or Louis ' chambers, but "invisible Asian" - later Russia performed this function (T.V. Igosheva "Aperture, stretched into Hell ..." or Hell music in the poetic cycle of N.Zabolotsky "Roebroeck in Mongolia" // N.A. Zabolotsky: pro et contra. The writers, critics and researchers` opinions of N. Zabolotsky`s personality and works: Anthology. - SPb., 2010. pp. 860-861). N.Ya. Danilevsky who stands at the origins of the organic understanding of history noted this circumstance, he cited last century European `s words, and that opinion was a consequence of a certain "mental cartography" when it seemed " from a distance " that "Russia throws its weight around, as a looming cloud, as some formidable nightmare" Danilevsky N.Ya. - M., 2000. p. 237). This allows analyzing the overall picture of the methodological specificity of logical and procedural modeling of history, to consider a dialogue of points of view: first of all, we must talk about classical models-images, contemporary strategy-projects and post-classical concepts of history. Consequently, it also makes sense to define the first thesis on the constructions of the social process: most often far from being equal - not only complementation but also opposition positions participate in the topologically presented modernity and post-modernity world view.

After all, the practice of history socio-humanitarian knowledge can acknowledge the possibility to combine the organic principle of haecceity with the requirements of the historical approach; it can prove not only the importance of the time factor but the presence of an objective variety of temporal properties of material systems. The theoretical description is unthinkable without the influence of socio-political and worldview ideals on the nature and direction of conceptual changes in science in connection with the historical evolution of the concepts of space and time. It is the question of the fact that the concepts of time and space are deeply rooted in the subject's history world. Their content includes both information about the history (time) of the object of research, and information about the history (time) of specific social goals and human needs, prompts its knowledge and practical transformation.

Based on the assumption that the leading importance of the humanistic content of scientific concepts in historical evolution, an individual is a real subject of research not only for the socio-humanitarian but also for the natural sciences - particularly when we address the processes of history that are impossible outside its material foundations. This point of view orients to the task to include the individual's problem in the field of analysis that regularities the organic evolution, it assumes that the entire social-historical practice is included in the full definition of the subject of science both as a criterion of truth and as a practical determinant of the value orientations of an individual.

It must be concluded that the appeal to organic history in the context of the epistemology of social processes implies the use of the terms "social time", "biological time", "physical time" - the goal is to characterize the specific differences over time (history) in organic nature and society. If the attempts to introduce the definition of specific historical time are regarded as unsuccessful, if the purpose is metaphorical expression of the processes of human development, that is continuous in reality within the limits of ordinary physical time, then it is necessary to raise a more general question - the question about the specifics of social life in general.

Once again it should be emphasized: social organic matter does not cease to be nature, but nature acquires special meanings in the social dimension. The history of life is not only and not even mainly, a chronological record of life, but a causative explanation of the genesis and the change of organic forms in the processes of evolution. The opposition of the historical approach to the evolutionary one is based on the view that the causative and historical explanations are incompatible. It leads from the history of living beings to the concept of " geologic-time scale", which reflects only those aspects of biological time that are related to its duration [11]. 
Factors mentioned in this study and determining the place and role of historical knowledge in culture may be demonstrated in the following figure 1:

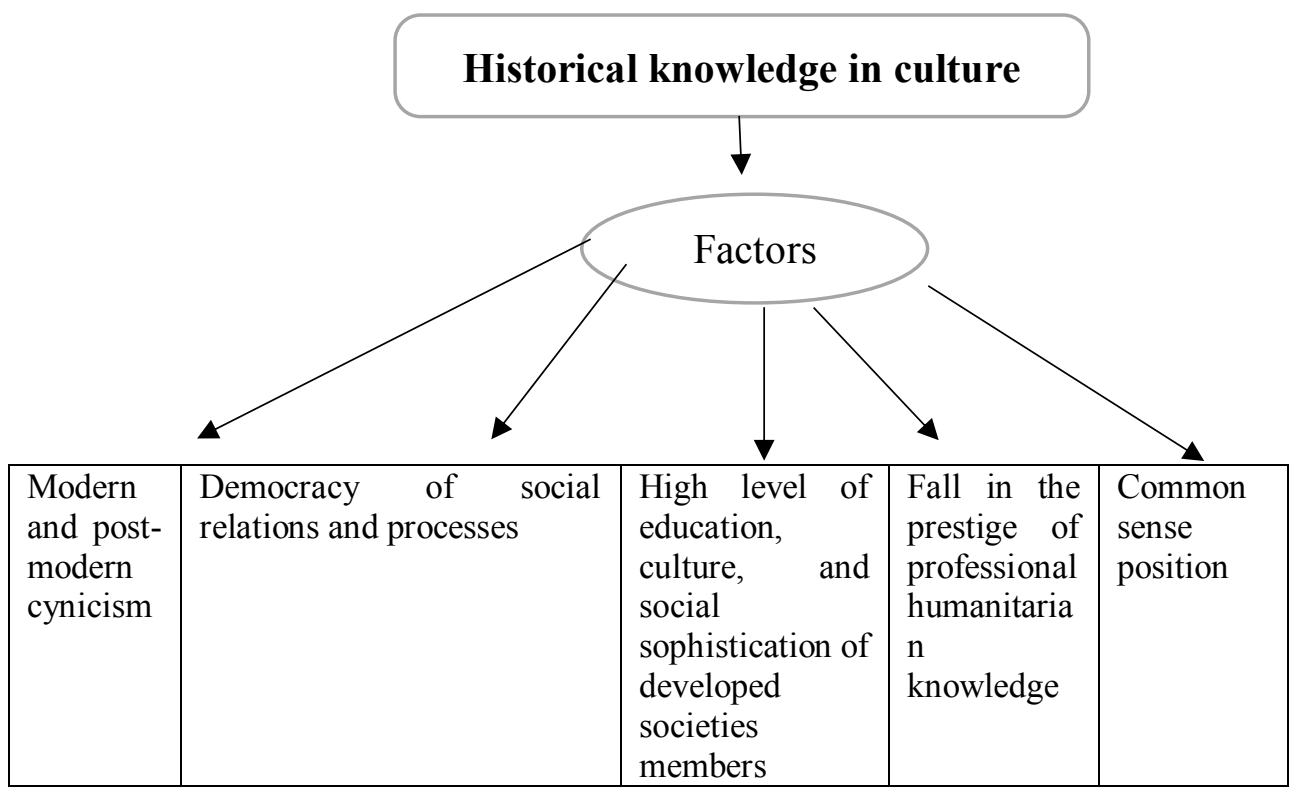

Fig. 1. Historical knowledge in culture.

But the fact that the evolutionary theory of life originates from the interpretation of time as an order of cause to effect dependencies that run according to the laws of continuity is not a basis for taking the thought of the organic beyond history. The erroneous identification of time with duration is the source of the absolute contraposition of the causative and historical approaches. Thus, the difficulties arise associated with the indistinguishability of physicalchemical and social evolution.

It is possible to remove this rigid opposition through the creation of a theory of biosocial evolution; social synergetics can provide greater assistance here: it is quite acceptable to talk about the homogeneity of the concepts of motion and duration that are applied in various fields of scientific knowledge. Accordingly, a subject must be defined - we can talk about it precisely because of the awareness of human dual nature that represents the obvious necessity of the interaction of physical and social subjects in the processes of history.

The actualization of model-images, contemporary strategies-projects, and post-classical concepts of history makes it possible to take into account all the basic universals and constants of modern epistemology of history. Thus, the research is directed against the abstract conception of history and a human in historical knowledge, which lacks epistemological certainty. This also suggests considering epistemological gaps in understanding the history - gaps that are consolidated by different methodological models of structuring the processes of history. After all, the very fact of gaps recognition and differences makes it possible to understand the complex conceptual unity of the philosophical representation of history and its subjects [12].

It must be stressed that the classical tradition also recognized the significance of differences in the historical process and subjects of history - in particular, Hegel was of the view of the opposition of morality and rectitude: if morality is the definition of the subjective will, then rectitude involves its objective realization in the forms of the moral spirit (family, civil society and state). And the fact that the starting point to understand the methodological 
specificity of theoretical modeling of history is images (N.Ya. Danilevsky), it tells us something about the importance of the theme of organic matter in today's concepts of history.

Thus, when analyzing the logical-processual organization of history, it may be justifiable to refer to the actualization of the "organic turn" not only in the art of modernity but also in the wider "life creation" of modernity, which is characteristic of modernity with its interest in the problems of "glocal" existence of cultures and communities [13]. Hence, even in the ultimate virtualized representation of the historical process the fact of organically-founded creativity, affect, and aspiration namely everything that is peculiar to biopower is important. On the contrary, the destruction of the organic of existence leads, as a rule, to one or another version of the ideologization of history, for example - the domination of ontological depreciate forms of unity, that are in a material-substantial and "commodity" form, when not "man as man" but a concrete "character" of the legitimate form of the structural-symbolic organization of history acts as the "subject of freedom".

In this regard, it is possible to comprehend differently about the "crisis of definitions" that modern thought is experiencing in addressing the problem of understanding history: if the question of the processes unity of the world as a whole is not a question of positive knowledge, there is always a constructive possibility to understand the dominant strategies of structuring historical processes. The fact is that history does not appear linearly, but as a form of manifestation of human potential (intellectual, volitional, emotional) - in any case, the representation of history contains the image of a holistic culture, which has the installation of the evaluation of existence. And it is not only a certain "spirit of the time", but also a creative aspiration for the future or "image of the world" - it is for the native philosophy of life (V.V. Rozanov) that the whole organic way of existence in history is significant.

On several occasions, we have noted the proximity of the organic-image representation of history and myth in this context should be supplemented by an analysis of new forms of structuring the integrity of historical consciousness and knowledge. C. Lévi-Strauss emphasized that the elements of mythological reflection are always between percepts and concepts and, therefore, connect the present existence with the projects of thinking [15]. This is expressed in the extremely weak distinction between the objective and the subjective precisely in their organic penetration into "the one is not". But in the process of moving away from the dominant mythological "symbolic animal" has an increasingly significant impact on the natural and subjective component of world images. In such cases, the subject-symbolic sphere receives as its essential definition the signs of symbolic activity of the historical subject - it is the symbolic activity of the support matrices of historical thinking that comes to the fore. And it is here, it should be emphasized, that the process of defining the actual subject of historical thinking is transferred to the system of subjectivity, which can be defined as identification [16].

About the reflexive significance of organic images in understanding contemporary historical processes, the idea of some retrospective actualization of the archaic should not arise, although this move is quite admissible, and it can be confirmed by several types of research. The definition of habitus, in sociology and social philosophy, includes conservative and archaic characteristics - habitus consists of the agent's subjective aspirations' limits, it sets the limits within which the agent creates his/her actions, it also reproduces routine, "unproblematic" actions [17]. The basis of Habitual Certainty in all variants of understanding is exactly the organic world perception, which is extremely actualized today in the situation of the "ecological turn" and humanistic-oriented ecosophy.

\section{Conclusions}

Here, it should be emphasized, the organic project is close to the ideas of Russian cosmism precisely in terms of understanding the correspondence of the existence of nature and 
humans. The Eurasian definition of developmental place that is close to cosmism contains a cosmic vertical in the sense of understanding the position of a human in space. The developmental place with all its rootedness in the landscape of life is atopic: one can speak of adjusted space. It cannot be perceived, experienced, it is initially identified. But the trace of this perception is preserved in any concrete topoi: space is everywhere: "the inhabitation of adjusted space is made before the subject of experience makes a conscious reference to the object as if relying on the intentionality of object space". It is important to take this into account when including the processes of history in the modern informational and communicative context.

Today you can find the organic history images in the space of topological reflection, this confirms the fact that organic thinking is very important. V.V. Savchuk writes that one can assume reasonably that the origin of the procedure of reflection lies in the archaic sacrifices that are at the heart of rituals and mysteries. Sacrifices essentially fulfilled the same role that was to obtain a reliable basis for the order of life, its safety, and its sense of purpose that was later fulfilled by reflection.

\section{References}

1. I. Prigozhin, Science, Civilization and Democracy (Philosophy and Sociology of Science and Technology: Yearbook, 1988 - 1989. - M., 1989)

2. V.V. Balakhonsky, Explanation of history: historical-philosophical, methodological and epistemological aspects ( $\mathrm{SPb}$.: RGPU im. A.I. Herzen; Penza: PSPU im. V.G. Belinsky, 1997)

3. M. Belilos, Freud and war (London, 2018) https://doi.org/10.4324/9780429474996

4. R. Tallise, Democracy After Liberlism. Pragmatism and Deliberative Politics (New York, 2005) https://doi.org/10.4324/9780203997680

5. R. Gottlieb, Environmental Crisis and Moral Life. In morality and the Environmental Crisis, Cambridge Studies in Religion, Philosophy and Society (Cambridge, Cambridge University Press, 2019) https://doi.org/10.1017/9781316493083.002

6. A. Edward, Page Climate change, Justice and future Generetions (Cheltenham, UKNorthampton USA, 2006) https://doi.org/10.4337/9781845424718

7. V.P. Bransky, The problem of the meaning of history (Art and Philosophy. Kaliningrad: Amber Garden, 2006)

8. M. Seymour, F. Love, Pasific Philosophical Quarterly 92, 2, 174-192 (2011) https://doi.org/10.1111/j.1468-0114.2011.01390.x

9. Fragments of the early Greek philosophers. - Translation / USSR Academy of Sciences, Institute of Philosophy. Edition pod. A.V. Lebedev. Resp. ed. and the author will enter. articles by I.D. Rozhansky (M.: Nauka, Part 1. From epic cosmogonies to the emergence of atomism, 1989)

10. P. Berger, T. Lukman, Social construction of reality: A treatise on the sociology of knowledge (M.: Madium, 2009)

11. R.S. Morris, Preventive Veterinary Medicine 122, 1-2, 242-252 (2015) https://doi.org/10.1016/j.prevetmed.2015.05.003

12. L. Westra, Environmental Justice and the rights of Ecological Refugees (London, 2009) https://doi.org/10.4324/9781849770088

13. G. Leibniz, Works (M.: Nauka, 1984) 
14. G. Bashlyar, Rational determinism and technical determinism (Philosophy and sociology of science and technology. M.: Nauka, 1986)

15. M. Kline, Mathematics. Loss of certainty (M.: Nauka, 1984)

16. M. Kimm, International Journal of Constitutional Law 6, 1, 117-136 (2008) https://doi.org/10.1093/icon/mom034

17. J.-W. Muller, Constitutional Patriotism (Princeton University Press, 2008) https://doi.org/10.1515/9781400828081 